\title{
Report of the AIIMS Neuroanaesthesia Update 2017, New Delhi, India
}

\author{
Varun Jain ${ }^{1} \quad$ Gyaninder P. Singh ${ }^{1} \quad$ Arvind Chaturvedi ${ }^{1}$
}

${ }^{1}$ Department of Neuroanaesthesiology and Critical Care, All India Institute of Medical Sciences, New Delhi, India

J Neuroanaesthesiol Crit Care 2018;5:42-44.

In continuation with previous years' success, Department of Neuroanaesthesiology and Critical Care, AIIMS conducted the fifth consecutive AIIMS Neuroanaesthesia Update from October 6 to 7, 2017, at the All India Institute of Medical Sciences (AIIMS), New Delhi, India. This was preceded by pre-conference workshops and followed by a 1.5-day "AIIMS Neurological Life Support" course for the first time. AIIMS Neuroanaesthesia Update started in 2013 with the idea of providing a unique platform to budding neuroenthusiasts to exchange knowledge and information, share experience, and interact with the masters in the field of neuroanesthesiology and neurocritical care. This year, the AIIMS Neuroanaesthesia Update was organized by Dr. Gyaninder Pal Singh (organizing secretary) under the leadership of Dr. Arvind Chaturvedi (organizing chairman). With 212 delegates, this was one of the most well-attended Neuroanaesthesia Update so far. The participants included neuroanesthesiologists, neurointensivists, fellows, residents, and medical students from all over the country.

The event started on October 5 with preconference workshops on transcranial Doppler (TCD) ultrasonography, intracranial pressure (ICP) monitoring, cerebral microdialysis, neurophysiology monitoring, and ultrasound-guided vascular access. The workshop on TCD was exclusively conducted as a full-day workshop by Dr. Girija Rath (AIIMS, New Delhi, India), Dr. Deepak Sharma (Seattle, Washington, United States), and Ms. Anne Moore (Seattle, Washington, United States). This was a unique experience for all the participants who had ample hands-on opportunities for performing TCD and learned the basics of this modality as well as its advanced use. The other neuromonitoring workshops included didactic lectures followed by demonstrations at the skill stations. Drs. Deepak Gupta, Charu Mahajan, Shweta Kedia, and Raghav Singla (AIIMS, New Delhi, India) conducted the workshops on ICP monitoring and cerebral microdialysis whereas Drs. Tumul Chowdhury, Marshall F. Wilkinson (Winnipeg, Canada), and Surya Kumar Dube (AIIMS, New Delhi, India) conducted workshop on neurophysiology monitoring. This was followed by hands-on teaching of central venous cannulation using ultrasonography on mannequin by
Address for correspondence Gyaninder P. Singh, MD, DM, Department of Neuroanaesthesiology and Critical Care, All India Institute of Medical Sciences, Neurosciences Centre, Room No. 711, 7th Floor, New Delhi 110029, India (e-mail: drsingh_gp@yahoo.co.in).

Drs. Niraj Kumar and Keshav Goyal (AIIMS, New Delhi, India). These workshops provided a valuable learning experience for the delegates.

On Friday, October 6, 2017, the session started with live telecast of neurosurgical cases from the neurosurgery operating theaters at $8.30 \mathrm{a} . \mathrm{m}$. The cases discussed included a motor strip glioma operated under awake craniotomy and a conus medullaris tumor of spinal cord operated in prone position along with neurophysiological monitoring. Experts in the theater included Drs. Parmod Bithal (Riyadh, Saudi Arabia), Arvind Chaturvedi (New Delhi, India), Deepak Sharma (Seattle, Washington, United States), and M. Radhakrishanan (Bengaluru, India) who very elaborately answered the queries of the audience. Drs. Hemant Bhagat (Chandigarh, India), Virendra Jain (Gurugram, India), and Varun Jain (New Delhi, India) moderated the discussion. There was an in-depth discussion about various perioperative aspects, and the delegates actively participated in discussion for management of these complex cases.

Lecture series commenced with session on "Technological Advancements" at 11.30 a.m. This session was chaired by Drs. Ashok Jaryal (New Delhi, India), K. J. Choudhary (New Delhi, India), and Jayashree Sood (New Delhi, India). Dr. Prasanna Bidkar (Puducherry, India) talked on "Use of Newer Technologies in Neuroanaesthesia Practice" and discussed various new additions to the neurosurgical anesthesia regarding monitoring, instruments and drugs, and how they are changing patient outcome. Dr. Marshall F Wilkinson (Winnipeg, Canada) discussed how neurophysiological monitoring is essential to neurosurgical practice during his talk on "Intraoperative Neuromonitoring-Is It Boon or Curse." Thereafter, Dr. D. Padmaja (Hyderabad, India) gave a very informative talk on "Anaesthesia and Developing BrainAn Insight." Next session on "Neurotrauma" began with a lecture by Dr. Parmod K. Bithal (Riyadh, Saudi Arabia) on "Paroxysmal Sympathetic Hyperactivity-A Storm after Acute Brain Injury," who explained the various manifestations of the condition and how to manage it. Dr. Deepak Sharma (Seattle, Washington, United States) discussed in detail the
DOI https://doi.org/ 10.1055/s-0037-1618326. ISSN 2348-0548.
Copyright $\odot 2018$ Indian Society of Neuroanaesthesiology and Critical Care
License terms

(9)(1) $\Theta \circledast$ 
challenges about the "Anaesthetic Management of Patient with Spine Injury" and Dr. Manish Marda (Ghaziabad, India) talked about the updated guidelines and recommendations in management of adult head injury cases. The chairpersons for this session were Drs. H. H. Dash (Gurugram, India), Rajiv Chawla (New Delhi, India), and Sobha Purohit (Jaipur, India).

Postlunch the conference continued with interactive case discussion on "Anesthetic Management of a Female with Second-Trimester Pregnancy Presenting with a Large Left Parasagittal Meningioma." Delegates actively participated and thoroughly enjoyed the session with expert inputs from Drs. Pragati Ganjoo (New Delhi, India) and S. Manikandan (Trivandrum, India). Drs. Keshav Goyal and Nitasha Mishra (New Delhi, India) moderated the session. Subsequently, there was a session on "Coagulation Abnormalities in Neurosurgery"-an ever-challenging situation for neurosurgeons and neuroanesthesiologist likewise. Drs. Kavita Sandhu (New Delhi, India), Swagata Tripathy(Bhubaneswar,India), and Saurabh Anand (Gurugram, India) very elaborately explained the management of various such situations. Drs. Deepak Sharma (Seattle, Washington, United States), Harsh Sapra (Gurugram, India), and Neerja Bharti (Chandigarh, India) chaired the session. Later, in a video session Dr. Prasanna Bidkar (Puducherry, India) demonstrated technique of placement of $\mathrm{SjVO}_{2}$ catheter and interpretation of values and Dr. Vishwas Malik (New Delhi, India) showed technique and tips for transesophageal echocardiography. Chairpersons for this session were Drs. Arvind Chaturvedi (New Delhi, India) and Sandeep Chauhan (New Delhi, India).

This was followed by the inaugural function that started with the lamp lightening ceremony. Dr. Randeep Guleria (Director, AIIMS, New Delhi, India) graced the occasion as the Chief Guest and Dr. H. H. Dash (ex-head, Department of Neuroanaesthesiology, AIIMS), was the Guest of Honor. Dr. A. K. Mahapatra (Chief, Neurosciences Center, AIIMS, India), Dr. Arvind Chaturvedi (organizing chairman), and Dr. Gyaninder Pal Singh (organizing secretary) shared the dais with the invited guests. Dr. Arvind Chaturvedi welcomed the guests, delegates, and faculties who came for the conference, and Dr. A. K. Mahapatra gave an insight on the activities and achievements of the Neuroanaesthesia Department and of Neurosciences Centre at AIIMS. Dr. H. H. Dash briefed the audience about his journey at AIIMS and hard work in setting up the department and its transformation over years to the present stage. Dr. Randeep Guleria appreciated the commendable work of Neuroanaesthesia Department and its contribution to the betterment of neurosciences patients and congratulated the organizing committee for hosting such an academic feast. Dr. Guleria distributed the Resident award for the year to Drs. Gaurav Singh Tomar and Barkha Bindu in recognition of their excellent performance throughout the year at this occasion. He also felicitated Dr. Deepak Sharma (Seattle, Washington, United States) for his contribution as a visiting professor to the institute. The ceremony ended with a vote of thanks by the organizing secretary.

Last quarter of the day started with a panel discussion on "Future Generation of Anaesthesiologists-What Professional Qualification Should We Aim for?" There was an interesting discussion on this very relevant topic in the present scenario by a team of learned and experienced panelists that included Drs. H. H. Dash (Gurugram, India), Sushma Bhatnagar (New Delhi, India), Rajeshwari Subramanium (New Delhi, India), Deepak Sharma (Seattle, Washington, United States), and V. Ponniah (Chennai, India). Dr. Mary Abraham (New Delhi, India) very well moderated the discussion by putting forward very important, focused, and relevant points covering almost every aspect. There was a general consensus that with growing technological advancement and more focused surgeries in the present era, it is also necessary for the anesthesiologists to choose their domain of subspecialization and achieve growth in their professional carrier. This was followed by the pros-and-cons debate on two topics. Dr. Sujoy Banik (Toronto, Canada) spoke in favor of conventional fluid therapy whereas Dr. Kiran Jangra (Chandigarh, India) favored goal directed fluid therapy in elective neurosurgical cases. Next, debate was between Drs. Rahul Yadav (New Delhi, India) and Vasudha Singhal (Gurugram, India) on "Balanced Salt Solution or Conventional Fluids for Neurosurgical Patients-What Should Be the Choice?" This session was chaired by Drs. Pragati Ganjoo (New Delhi, India), Shashi Srivastava (Lucknow, India), M. Srilata (Hyderabad, India), and Arvind Arya (New Delhi, India). The day ended with a gala dinner and live music where the delegates enjoyed the gathering at a casual relaxing environment.

Last day of conference, October 7, Saturday, started with lectures on "Cerebral Autoregulation" by Dr. Ramamani Mariappan (Vellore, India), "Biomarkers of Neuronal Injury" by Dr. H. K. Venkatesh (Bengaluru, India), and "Translational Research in Neuroanaesthesia” by Dr. V.J. Ramesh (Bengaluru, India). Drs. Parmod Bithal (Riyadh, Saudi Arabia), R. Batra (New Delhi, India), and G. Parameswara (Bengaluru, India) chaired the session. This was followed by session on "Paediatric Neuroanaesthesia" chaired by Drs. M. K. Arora (New Delhi, India), R. B. Singh (Varanasi, India), and R. S. Chauhan (New Delhi, India). Dr. Mihir Pandia (New Delhi, India) discussed the "Practical Considerations in Peadiatric Neuroanaesthesia Practice" and Dr. Monica Tandon (New Delhi, India) dwelt on the "Difficult Paediatric Airway Scenarios."

After the refreshments break, session resumed with short talks on few important drugs and their present status in neuroanesthesia practice. Dr. S. Manikandan (Trivandrum, India) talked about dexmedetomidine. Dr. Bhavna Hooda (New Delhi, India) talked about tranexamic acid and Dr. Ankur Luthra (Chandigarh, India) discussed about Ketamine. Drs. Sashi Srivastava (Lucknow, India), H. K. Venkatesh, and Mukul Jain (Noida, India) chaired the session. After that, there were very interesting talks on "Brain-Heart Interactions: Is It Bidirectional?” by Dr. Tumul Chowdhury (Winnipeg, Canada) and "Brain-Lung Crosstalk: A Complex Interaction!” by Dr. M. Radhakrishnan (Bengaluru, India). Both the speakers demonstrated with several examples on how the heart and lungs play a tandem role with the brain in defining the disease process. The chairpersons for this session were Drs. V. J. Ramesh (Bengaluru, India), Kavita Sandhu (New Delhi, India), and Hemant Bhagat (Chandigarh, India). 
Next was the session on "Neurointensive Care" where two commonly encountered scenarios in neurointensive care units were discussed. Dr. Nidhi Gupta (New Delhi, India), discussed about nonconvulsive status epilepticus and how to diagnose it when in dilemma whereas Dr. V. Ponniah (Chennai, India) discussed about recent advances in managing patients of acute ischemic stroke. Drs. Monica Tandon (New Delhi, India), Jaya Wanchoo (Gurugram, India), and Yash Javeri (New Delhi, India) were the chairpersons for this session. This was followed by discussion on emergency situations we may encounter in operating theater, and Drs. Harsh Sapra (Gurugram, India), Ratan Chelani (Mumbai, India), and Tumul Chowdhury (Canada, India) chaired this session. Dr. Ranadhir Mitra (Bhubaneswar, India) spoke about management of "Intraoperative Cardiac Arrest during CPA surgery in Lateral Position with Head Fixed with Pins," Dr. Srilata M (Hyderabad, India) talked about "Airway Management of Seizing Patient during Awake Craniotomy for Epilepsy Surgery." Dr. V. B. Sharma (Chandigarh, India) discussed about "Catastrophic Venous Air Embolism in an 8-Year-Child Undergoing Posterior Fossa Surgery in Sitting Position." The last session had two video lectures where Dr. Renu Bala (Rohtak, India) demonstrated how to perform "ICP Measurement using Transocular Ultrasonography" and Dr. Navdeep Sokhal (New Delhi, India) demonstrated "USG-Guided Arterial Cannulation" by video presentations. Drs. Rahul Yadav (New Delhi, India) and Manish Marda (Ghaziabad, India) chaired this session.

Besides all this, there was an e-poster session where delegates from various parts of the country presented their research work. The posters were evaluated by experts for the best paper awards. Judges for poster session were Drs. V. Ponniah (Chennai, India), Hemanshu Prabhakar (New Delhi, India), Tumul Chowdhury (Winnipeg, Canada), M. Ramamani (Vellore, India), Pragati Ganjoo (New Delhi, India), and S. Manikandan (Trivandrum, India). The coordinators of the session were Drs. Navdeep Shokal and Indu Kapoor (New Delhi, India). A total of 25 e-posters were presented, which showcased at breath the various neuroanesthesia researches going on at different centers. Postgraduate students and fellows also participated in quiz competition conducted by quiz masters Drs. Tumul Chowdhury (Winnipeg, Canada), Surya Dube, and Varun Jain (New Delhi, India). Thirteen teams participated for the quiz, and the three teams scoring the highest points were rewarded.

After the plenary session, the fifth AIIMS Neuroanaesthesia Meet concluded with prize distribution to the quiz and best paper award winners. Thirty participants who had enrolled in the "AIIMS Neurological Life Support" continued to attend the course over the next 1.5 days. The organizing secretary thanked all the delegates and invited them to next year's meet. Participants appreciated the exhaustive yet interesting and time-bound scientific schedule, and lauded the efforts of organizing committee and showed eagerness to come again for the next year's meet.

\section{Funding \\ None.}

\section{Conflict of Interest}

None. 